\title{
Molecular Dynamics Simulation of the Interaction between Common Metal Ions and Humic Acids
}

\author{
Xu Wu, Yu Xia, Lianhua Yuan, Kaiyu Xia, Yu Jiang, Na Li and Xuwen He * \\ School of Chemical and Environmental Engineering, China University of Mining and Technology (Beijing), \\ Beijing 100083, China; ZQT1800302065G@cumtb.edu.cn (X.W.); 201945@cumtb.edu.cn (Y.X.); \\ SQT1900302040@cumtb.edu.cn (L.Y.); ZQT1800302066G@cumtb.edu.cn (K.X.); \\ ZQT1800302040G@cumtb.edu.cn (Y.J.); ZQD1900302055G@cumtb.edu.cn (N.L.) \\ * Correspondence: 108137@cumtb.edu.cn; Tel.: +86-010-62331360
}

Received: 13 September 2020; Accepted: 9 November 2020; Published: 16 November 2020

\begin{abstract}
Humic acids (HAs) have important environmental and geochemical effects on soil, water environments and sediment. HAs strongly complex some metal ions, which affects the migration of metal ions and the colloidal aggregation of HA. Here, the complexation of $\mathrm{Ca}^{2+}$ and $\mathrm{Mg}^{2+}$ with HA in aqueous solution under neutral conditions has been systematically studied by molecular dynamics (MD) simulation. The results show that the aggregation of HA is caused by the complexation of HA and metal ions, mainly due to the intermolecular bridging between $\mathrm{Ca}^{2+}$, $\mathrm{Mg}^{2+}$ and $\mathrm{COO}^{-}$groups. Monodentate and bidentate coordinations have been found between $\mathrm{Ca}^{2+}$ and $\mathrm{COO}^{-}$groups of different HA molecules in the same simulation system. $\mathrm{Mg}^{2+}$ only has a monodentate coordination with $\mathrm{COO}^{-}$group.
\end{abstract}

Keywords: humic acids; metal ions; aggregation; molecular dynamics simulation

\section{Introduction}

Humic acids (HAs) are a common chemical component in soil, groundwater and sediment. The acids are ubiquitous in the environment and are mainly formed by the weathering and decay of plants [1-3]. Complexes of HAs with inorganic and organic compounds have different chemical and biological stability and play an important role in the purification and advanced treatment of petrochemical wastewater. HA is considered to be the main pollution source of ultrafiltration (UF), nanofiltration (NF) and reverse osmosis (RO) membranes, which directly leads to the formation of the surface regulation layer ("biofouling") to which microorganisms are attached [4-6]. HA can also combine with metal ions and form metal complexes in natural water and petrochemical wastewater, thus affecting the solubility, fluidity, toxicity and bioavailability of metals [7]. Some research has reported the effects of $\mathrm{pH}$ [8], metal species [9] and temperature [10] on the aggregation of HA. However, the effect of metal ion types on the aggregation behaviors of HA has not yet been clearly discussed. The strong complexation between HA and metal ions plays a fundamental role in the treatment of metal pollution and the elimination of HA in solution [11,12].

Most studies on aggregation have only focused on macroscopic experimental phenomena due to different experimental variables, such as the different aggregate sizes and electrokinetic properties of HA colloids. The relationship between different critical coagulation concentration (CCC) values and the adhesion efficiency of HA aggregates due to the presence of typical metal ions has rarely been studied [13]. Moreover, different types of metal ions may have different effects on the aggregation of HA, even if they have the same valence state. Recent analysis revealed that the aggregation behaviors and binding interactions of colloids rely on metal cation valence as well as cation types. For example, Stirpe et al. [14] found that $\mathrm{Cu}^{2+}$ demonstrates greater influence than $\mathrm{Zn}^{2+}$ in modifying the kinetics 
of protein aggregation. Kalinichev et al. [15] studied the molecular dynamics (MD) simulation of the interaction between natural organic compounds $(\mathrm{NOM})$ and metal ions $\left(\mathrm{Na}^{+}, \mathrm{Cs}^{+}, \mathrm{Mg}^{2+}, \mathrm{Ca}^{2+}\right)$. The results showed that monovalent ions form very weak outer spherical complexes with NOM, and $\mathrm{Mg}^{2+}$ has a weak interaction with NOM because of its strong hydration shell; the binding of $\mathrm{Ca}^{2+}$ with NOM was the strongest of all studied ions. The above results were obtained only in terms of the radial distribution functions (RDFs) and coordination number, However, the interaction energy was not calculated. Ai et al. [16] studied the aggregation mechanism of HA with different heavy metal ions $\left(\mathrm{Ag}^{+}\right.$, $\left.\mathrm{Cd}^{2+}, \mathrm{Cr}^{3+}\right)$ and common metal ions $\left(\mathrm{Na}^{+}, \mathrm{Ca}^{2+}, \mathrm{Al}^{3+}\right)$ by $\mathrm{MD}$ simulation. However, the aggregation of HA with the same valence state has been less widely discussed. In addition, the internal mechanism of the aggregation process between HA and metal aggregates, such as an intramolecular or intermolecular binding interaction, has not been studied thoroughly. A comprehensive study of the binding behavior of metal ions with HA, especially different aggregations of HA, will increase our understanding of their impacts in petrochemical wastewater treatment. In the present study, $\mathrm{Ca}^{2+}$ and $\mathrm{Mg}^{2+}$ with the same valence state in concentrated petrochemical wastewater were chosen to evaluate the interaction of HA under neutral conditions [17]. To characterize the aggregation process of HA metal complexes, the interaction energy, RDFs, solvent accessible surface areas (SASAs) and hydrogen bonds of different metal ion complexes were analyzed by using MD simulation. These analyses enhance our understanding the structure, kinetics and aggregation characteristics of $\mathrm{HA}$, which is crucial to evaluate the application of $\mathrm{HA}$ in the removal process of metal ions from petrochemical wastewater and to reduce membrane pollution.

\section{Models and Computational Methods}

The Temple-Northeastern-Birmingham (TNB) $[18,19]$ model is usually used as a typical representative of HA in experiments and is successfully used in simulation because TNB is similar to HA and its MD simulation is simple $[15,16,20]$. The molecular weight of the TNB model is 753 Daltons, which is in the range of the most common HA molecules [21]. As shown in Figure 1a, the TNB model contains three carboxyl groups, three carbonyl groups, two phenolic groups, two amino groups and four other R-OH alcohol groups [16,21,22]. Figure 1a shows the size, composition and molecular structure of the TNB model $\left(\mathrm{C}_{36} \mathrm{H}_{40} \mathrm{O}_{16} \mathrm{~N}_{2}\right)$, and Figure $1 \mathrm{~b}$ shows the morphology of the TNB model in simulation software (Materials Studio 2019, Accelrys, San Diego, USA). As shown in Table 1, the experimental characterization of TNB model is extremely consistent with that of other HA models [23].

In the simulation, functional groups of HA were shown to have different protonation states under different $\mathrm{pH}$ conditions. The experimental results show that the three carboxyl groups of TNB $(\mathrm{pKa}=4 \sim 5)$ are completely deprotonated under neutral conditions, while the two phenolic groups are completely protonated under neutral conditions $(\mathrm{pKa} \approx 9)$ [27]. Because the amino group of the TNB model is located on the benzene ring, which is similar to aniline, according to the pKa value of aniline ( $\mathrm{pKa}=4.6)$, the amino group of TNB model can always remain electrically neutral $\left(\mathrm{NH}_{2}\right)$ [16]. These deprotonated carboxyl groups are the main source of negative charge in the simulated system at neutral $\mathrm{pH}$ and are also important binding sites of metal ions in the aggregation state because of the charge attraction to deprotonated sites. In this study, the force field used was COMPASS [26], which is commonly used in organic compounds. The force field can be regarded as the empirical expression of the potential energy surface, which is the basis of molecular mechanics, MD and the Monte Carlo simulation. In MD simulation, the force field method is used to calculate the energy of the system according to the position of atoms. Compared with the previous quantum mechanical method, it can save a large amount of time and can be used to perform calculations for systems containing tens of thousands of particles. The COMPASS force field can accurately simulate various organic and inorganic substances in a gaseous state, liquid state or solid state [28,29]. Firstly, energy minimization was performed for TNB and water molecules, respectively [26]. The optimized O-H bond length of water molecules was $0.957 \AA$, and the $\mathrm{H}-\mathrm{O}-\mathrm{H}$ angle was $104.526^{\circ}$. A simple point charge (SPC) was used by building a water model to describe the water molecules in the simulation system, and then 
four TNB molecules were randomly inserted into a water box (density: $997 \mathrm{~kg} / \mathrm{m}^{3}$ [30]) by using an AC module. The simulation system had 12 negative charges. Then, six divalent cations $\left(\mathrm{Ca}^{2+} / \mathrm{Mg}^{2+}\right)$ were added into the above frame to compensate for excess negative charges. The Smart method was used to minimize the energy of the system. The Smart method integrates the steepest descent method, conjugate gradient method and Newton method. It can shorten the time required for configuration optimization and improve the optimization accuracy. An NPT ensemble was used in the simulation system. The temperature was controlled at $298 \mathrm{~K}$ by Andersen [26]. The initial velocity of each molecule was randomly generated by the distribution. The Ewald method was used to calculate the long-range electrostatic interaction, and an atom-based method was used to calculate the van der Waals interaction. The time step was $1 \mathrm{fs}$, and the trajectory information was recorded every $1 \mathrm{ps}$. The total simulation time was $1 \mathrm{~ns}$. All MD simulation systems were completed by using the Materials Studio 2019 package. In the simulation system, the nitrogen and oxygen in the second period of the periodic table of elements, directly connected to the hydrogen atom, were hydrogen bonded, including $-\mathrm{OH},-\mathrm{COO}^{-},-\mathrm{NH}_{2}$ and water molecules. The interaction energy and the number of hydrogen bonds were calculated using a self-made program.

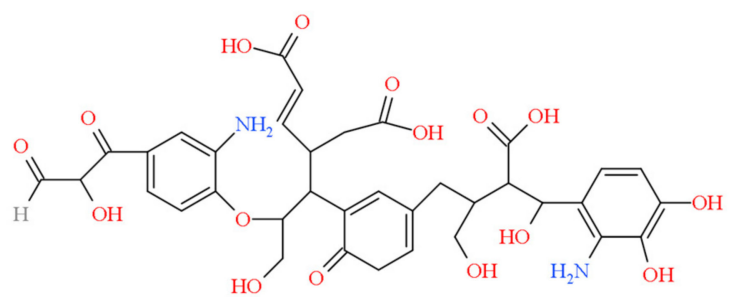

(a)

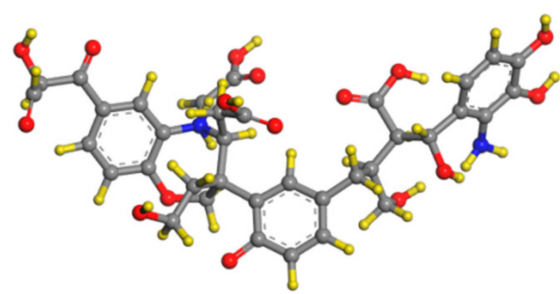

(b)

Figure 1. Molecular structure of the Temple-Northeastern-Birmingham (TNB) model: (a) the structural formula of the TNB model; (b) the morphology of TNB model in simulation software. C (gray), O (red), $\mathrm{H}$ (yellow), N (blue).

Table 1. Experimental data of several humic acid (HA) molecular models.

\begin{tabular}{cccccccc}
\hline & $\mathbf{C}(\mathbf{w t .} \%)$ & $\mathbf{H}(\mathbf{w t} . \%)$ & $\mathbf{O}(\mathbf{w t .} \%)$ & $\mathbf{N ~ ( w t . \% )}$ & $\mathbf{S ~ ( w t . \% )}$ & $\mathbf{P}$ (wt.\%) & Reference \\
\hline TNB & 57.4 & 4.9 & 34.0 & 3.7 & - & - & {$[18]$} \\
Steelink & 59.5 & 5.2 & 33.5 & 1.8 & - & - & {$[24]$} \\
CSHA\#9 & 53.3 & 4.2 & 37.9 & 1.4 & 3.0 & - & {$[25]$} \\
Schulten & 51.5 & 4.0 & 41.8 & 2.0 & 0.6 & - & {$[26]$} \\
Exp. (SRHA) & 52.5 & 4.2 & 42.7 & 1.1 & 0.6 & 0.02 & {$[27]$} \\
\hline
\end{tabular}

In order to study the interaction between metal ions and TNB to reveal the difference in the translational mobility of ions around TNB molecules, different ion situations were chosen to analyze the diffusion coefficients of ions and TNB in the first $200 \mathrm{ps}$. The mean square displacement (MSD) [31,32] and diffusion coefficient $(D)[33]$ were obtained by fitting the curves. MSD was determined by

$$
6 D t=\left\langle\left|\mathrm{r}_{j}(t)-\mathrm{r}_{j}(0)\right|^{2}>\right.
$$

and $(D)$ was defined as

$$
D=\lim _{t \rightarrow \infty} \frac{1}{6 t}<\left|r_{j}(t)-r_{j}(0)\right|^{2}>
$$

where $r_{j}(t)$ is the atomic position of the target molecule at time $t$ and $<>$ indicates that all ion position parameters in the simulated system are averaged.

The interaction between TNB and metal ions was investigated because RDFs enable a general understanding of the distance and strength of the interaction between atoms. Therefore, in this 
study, RDFs analysis was carried out. The coordination number $(n)[34,35]$ refers to the number of coordination atoms around the central atom in a compound, and the $n$ of atomic interaction was obtained by the following equation:

$$
n=\int_{R_{1}}^{R_{2}} 4 \pi r^{2} \rho g(r) \mathrm{d} r
$$

where $n$ is the number of specific atoms in a peak, $r$ is the distance from the atom to the target atom, $\rho$ is the number density of the atom in the main phase and $\mathrm{g}(r)$ is the RDFs from the atom to the target atom.

\section{Results and Discussion}

\subsection{System Equilibrium and Interaction Energy}

The completed simulation system is shown in Figure 2a,b. The distance between the metals and TNB is very small, and they become aggregated. Important criteria determining whether the NPT simulation system was in equilibrium were as follows: (1) temperature balance-the standard deviation of temperature change was required to be less than $5 \%$; (2) energy balance-the energy was required to be constant or to fluctuate along a constant value; and (3) density balance-the density change was required to be less than $5 \%$. Through calculation, it was found that the temperature, energy and density deviation of the last 200 ps were less than $3 \%$, and the system reached equilibrium. Therefore, the subsequent analysis could be carried out, and the data were valid.

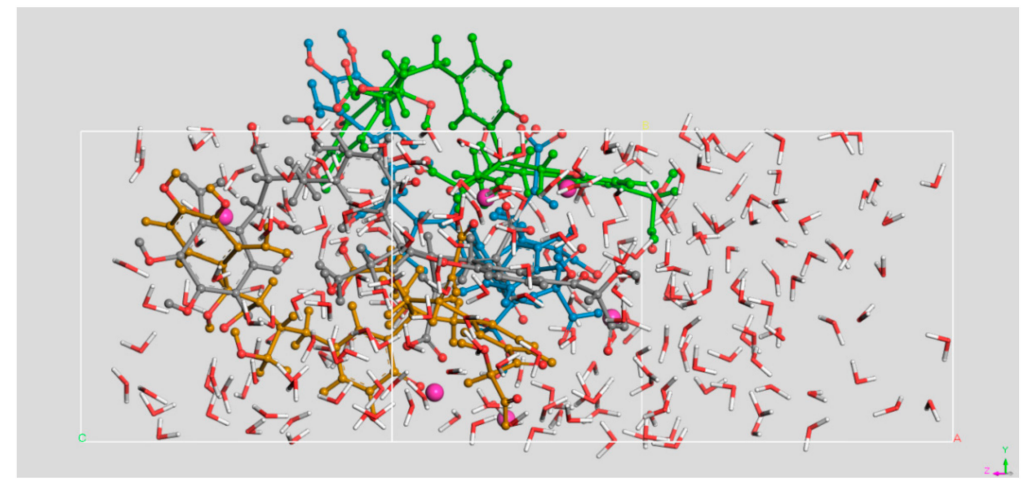

(a)

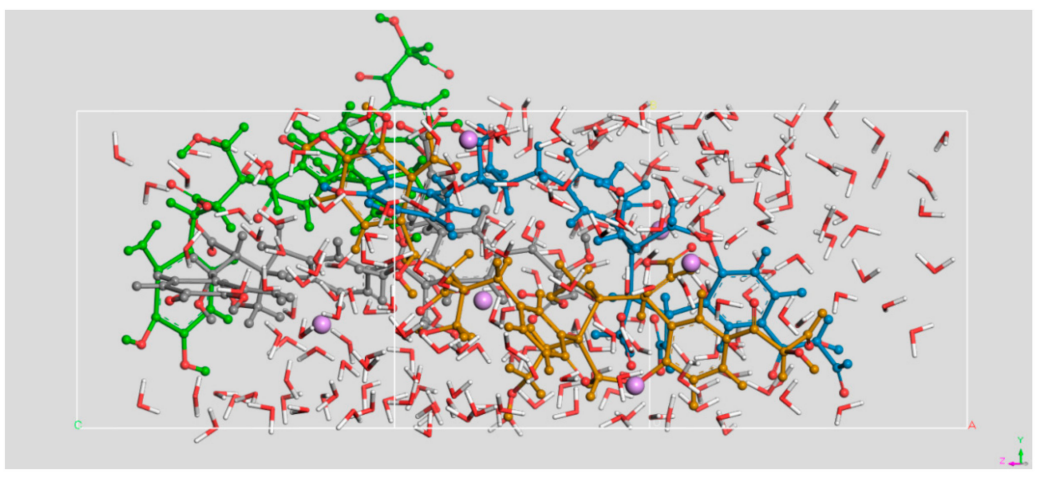

(b)

Figure 2. Snapshots of (a) $\mathrm{Ca}^{2+}-\mathrm{TNB}(\mathbf{b}) \mathrm{Mg}^{2+}-\mathrm{TNB}$ equilibrium after molecular dynamic simulation. $\mathrm{Ca}^{2+}$ (pink), $\mathrm{Mg}^{2+}$ (purple), $\mathrm{O}$ (red).

Figure 3 shows the MSD of metal ions and TNB in different systems. It can be seen that TNB in water molecules has a low migration ability, which is mainly caused by the strong hydrogen bonds and electrostatic interaction between TNB and water. The corresponding $D$ of molecules and 
ions are calculated and listed in Table 2. A comparison between $\mathrm{Ca}^{2+}-\mathrm{TNB}$ and $\mathrm{Mg}^{2+}-\mathrm{TNB}$ shows a larger $D$ value of $\mathrm{Ca}^{2+}$ and a stronger diffusion ability of $\mathrm{Ca}^{2+}$, which is mainly because $\mathrm{Mg}^{2+}$ is more electronegative than $\mathrm{Ca}^{2+}$. The stronger electronegativity of $\mathrm{Mg}^{2+}$ leads to a smaller ion radius. Therefore, the charge of $\mathrm{Mg}^{2+}$ nucleus is higher. $\mathrm{Mg}^{2+}$ has a stronger electric field strength and a greater interaction with water molecules [13] (Figure 4).

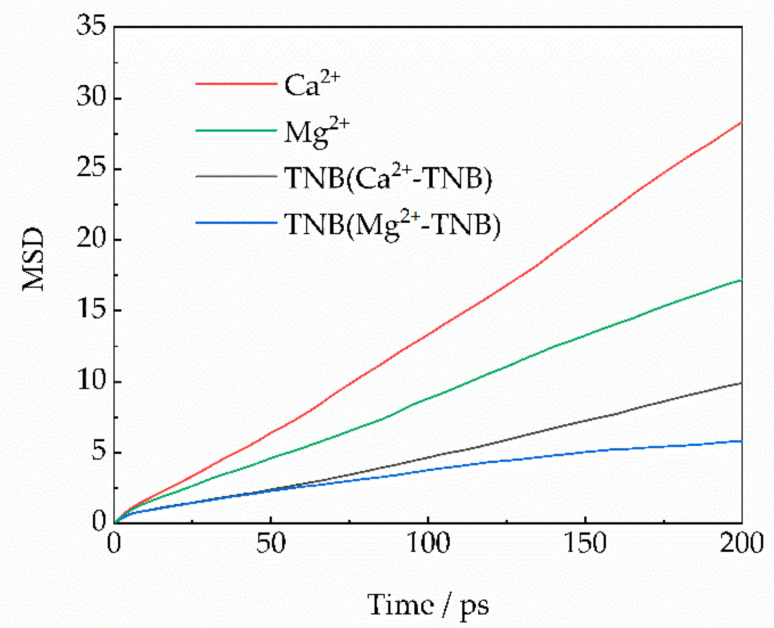

Figure 3. Mean square displacement (MSD) of TNB and ions in different systems.

Table 2. Diffusion coefficients of TNB and ions in different systems.

\begin{tabular}{ccccc}
\hline & $\mathbf{C a}^{2+}$ & $\mathbf{M g}^{2+}$ & TNB $\left(\mathrm{Ca}^{2+}-\mathbf{T N B}\right)$ & $\left.\mathbf{T N B} \mathbf{( M g}^{2+}-\mathrm{TNB}\right)$ \\
\hline$D / 10^{-9} \mathrm{~m}^{2} \mathrm{~s}^{-1}$ & 1.179 & 0.709 & 0.399 & 0.230 \\
$\mathrm{R}^{2}$ & 0.998 & 0.999 & 0.996 & 0.983 \\
\hline
\end{tabular}

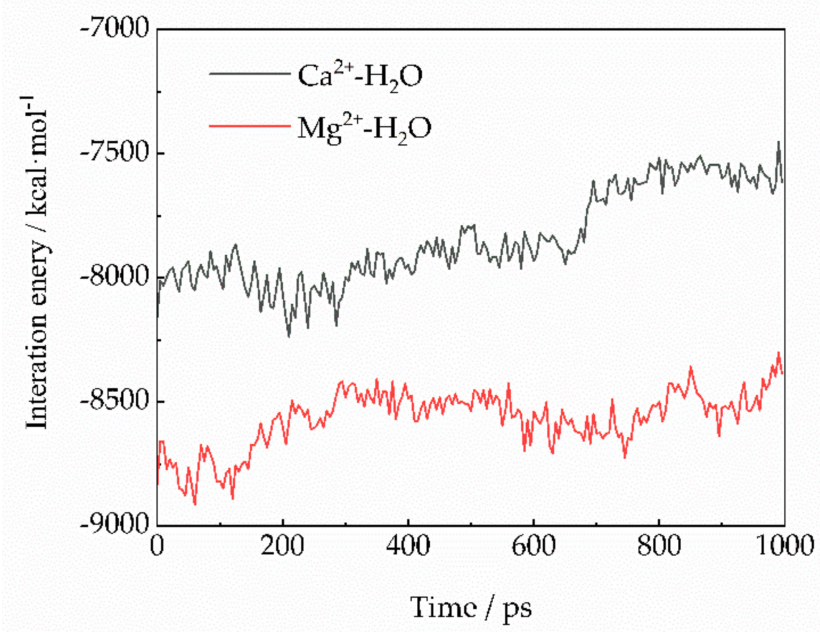

Figure 4. Interaction energy between ions and water molecules.

\subsection{RDFs and Coordination Number}

RDFs and coordination numbers are calculated and summarized in Figure 5 and Table 3. As shown in Figure 5a, the first sharp peaks of " $\mathrm{Ca}^{2+}$-carboxyl", "Ca ${ }^{2+}$-water" and " $\mathrm{Ca}^{2+}$-hydroxyl" are located in $\mathrm{d}_{\mathrm{Ca}, \text { carboxyl }}{ }^{\mathrm{I}}=2.1 \AA \mathrm{d}_{\mathrm{Ca}, \text { water }}{ }^{\mathrm{I}}=2.3 \AA$ and $\mathrm{d}_{\mathrm{Ca}, \mathrm{OH}}=4.1 \AA$, respectively $\left(\mathrm{d}_{\mathrm{A}, \mathrm{B}}{ }^{\mathrm{I}}\right.$ : distance of first sharp peaks between $\mathrm{A}$ and $\mathrm{B}$ ). Each $\mathrm{Ca}^{2+}$ has $1.59 \mathrm{O}$ atoms of the $\mathrm{COO}^{-}$groups, $0.27 \mathrm{O}$ atoms of hydroxyl and $0.57 \mathrm{H}_{2} \mathrm{O}$ molecules in the first coordination shell on average. The second peaks of "Ca ${ }^{2+}$-carboxyl" and " $\mathrm{Ca}^{2+}$-water" are located in $\mathrm{d}_{\mathrm{Ca} \text {,carboxyl }}{ }^{\mathrm{II}}=3.7 \AA$ and $\mathrm{d}_{\mathrm{Ca} \text {, water }}$ II $=4.5 \AA$. Each $\mathrm{Ca}^{2+}$ has $0.10 \mathrm{O}$ atoms of the $\mathrm{COO}^{-}$groups and $0.30 \mathrm{H}_{2} \mathrm{O}$ molecules in the second coordination shell. 
The RDFs of $\mathrm{Mg}^{2+}$ are shown in Figure 5b; the first sharp peaks of " $\mathrm{Mg}^{2+}$-carboxyl" and " $\mathrm{Mg}^{2+}$-water" are located in $\mathrm{d}_{\mathrm{Mg} \text {,carboxyl }}{ }^{\mathrm{I}}=1.7 \AA$ and $\mathrm{d}_{\mathrm{Mg} \text {,water }}{ }^{\mathrm{I}}=1.9 \AA$. Each $\mathrm{Mg}^{2+}$ has $0.92 \mathrm{O}$ atoms $\left(\mathrm{COO}^{-}\right)$ and $0.74 \mathrm{H}_{2} \mathrm{O}$ molecules in the first coordination shell on average. There are $0.31 \mathrm{O}$ atoms $\left(\mathrm{COO}^{-}\right)$ and $0.27 \mathrm{H}_{2} \mathrm{O}$ molecules in the second coordination shell of $\mathrm{Mg}^{2+}$ on average $\left(\mathrm{d}_{\mathrm{Mg} \text {, carboxyl }} \mathrm{II}=3.5 \AA\right.$, $\mathrm{d}_{\mathrm{Mg} \text {,water }}{ }^{\mathrm{II}}=4.3 \AA$ ). Because the electronegativity of $\mathrm{Mg}^{2+}$ is greater than that of $\mathrm{Ca}^{2+}$, the shell of $\mathrm{Mg}^{2+}$ hydration $\left(\mathrm{d}_{\mathrm{Mg} \text {,water }}{ }^{\mathrm{I}}=1.9 \AA \mathrm{d}_{\mathrm{Mg} \text {,water }}{ }^{\mathrm{II}}=4.3 \AA\right)$ is thinner than that of $\mathrm{Ca}^{2+}\left(\mathrm{d}_{\mathrm{Ca} \text {,water }}{ }^{\mathrm{I}}=2.3 \AA\right.$, $\mathrm{d}_{\text {Ca,water }}{ }^{\mathrm{II}}=4.5 \AA$ ) [13]. The number of water molecules in the first hydration shell is an effective parameter for evaluating the interaction strength between polar groups and water [34]. The total coordination number of $\mathrm{Ca}^{2+}$ and $\mathrm{H}_{2} \mathrm{O}$ is 0.87 , which is smaller than that of $\mathrm{Mg}^{2+}$ and $\mathrm{H}_{2} \mathrm{O}(1.01)$. The binding of water molecules to $\mathrm{Ca}^{2+}$ is not as close as other combinations because the charge radius ratio of $\mathrm{Ca}^{2+}$ is smaller than that of $\mathrm{Mg}^{2+}$, which is consistent with the above analysis. It can also be seen that the distance between different shell layers of the hydration shell is about $2.2 \sim 2.4 \AA$, which is very close to the length of the hydrogen bond. Therefore, it is thought that the water molecules in the first water shell can form hydrogen bonds with the water molecules in the second water shell. In other words, the first and second water shells are connected by hydrogen bonds [31]. The coordination number of $\mathrm{Mg}^{2+}$ and the hydroxyl group is $0.25\left(\mathrm{~d}_{\mathrm{Mg}, \mathrm{OH}}=3.7 \AA\right)$; this is smaller than that of $\mathrm{Ca}^{2+}$ and the hydroxyl group (0.27), and the binding ability of these two ions to the hydroxyl group is low.

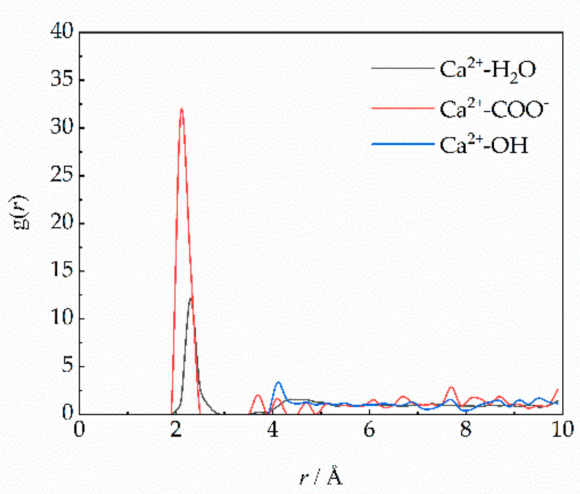

(a)

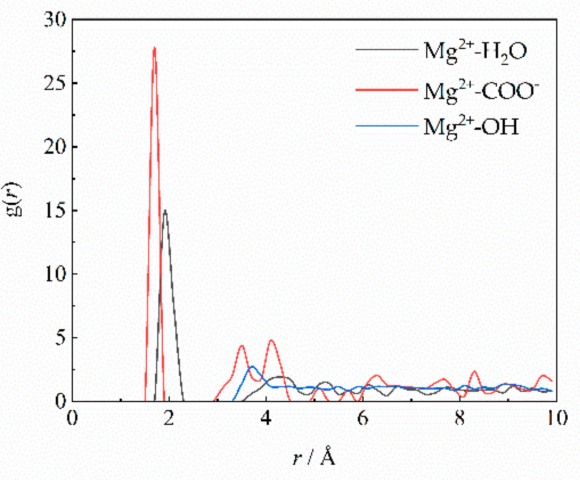

(b)

Figure 5. Radial distribution functions of $(\mathbf{a}) \mathrm{Ca}^{2+}$ and (b) $\mathrm{Mg}^{2+}$ associated with $\mathrm{O}$ atoms of $\mathrm{COO}^{-}$and $\mathrm{O}$ atoms of hydroxy and water molecules.

Table 3. Radii of the first and second coordination shells around $\mathrm{Ca}^{2+} / \mathrm{Mg}^{2+}$ and coordination numbers of association with $\mathrm{COO}^{-}$and $\mathrm{OH}$ of TNB and water molecules.

\begin{tabular}{lcccccc}
\hline System & Hydrophilic Group & Peak $_{\mathbf{1}} / \mathbf{A}$ & Peak $_{\mathbf{2}} / \mathbf{A}$ & $\mathbf{n}_{\mathbf{1}}$ & $\mathbf{n}_{\mathbf{2}}$ & Total \\
\hline \multirow{3}{*}{$\mathrm{Ca}^{2+}-\mathrm{TNB}$} & $\mathrm{COO}^{-}$ & 2.1 & 3.7 & 1.59 & 0.10 & 1.69 \\
& $\mathrm{OH}$ & 4.1 & $/$ & 0.27 & $/$ & 0.27 \\
& $\mathrm{H}_{2} \mathrm{O}$ & 2.3 & 4.5 & 0.57 & 0.30 & 0.87 \\
\hline \multirow{3}{*}{$\mathrm{Mg}^{2+}-\mathrm{TNB}$} & $\mathrm{COO}^{-}$ & 1.7 & 3.5 & 0.92 & 0.31 & 1.23 \\
& $\mathrm{OH}$ & 3.7 & $/$ & 0.25 & $/$ & 0.25 \\
& $\mathrm{H}_{2} \mathrm{O}$ & 1.9 & 4.3 & 0.74 & 0.27 & 1.01 \\
\hline
\end{tabular}

All the above results can be further verified by the geometric analysis of a snapshot from the MD simulation, which is shown in Figure 6. The snapshot of simulated trajectories in Figure 6a shows that both monodentate $(2.133 \AA$ ) and bidentate $(2.029 \AA$ and $2.154 \AA$ ) coordination were present between $\mathrm{Ca}^{2+}$ and $\mathrm{COO}^{-}$groups of different TNB molecules. The geometry of the $\mathrm{Ca}^{2+}-\mathrm{TNB}$ complex reveals the strong bidentate coordination of $\mathrm{COO}^{-}$groups of two different TNB molecules to $\mathrm{Ca}^{2+}$. This shows that $\mathrm{Ca}^{2+}$ is complexed with two or more carboxylic acids, and this structure is consistent with previous simulation results [26,36]. In Figure 6b, it is seen that a monodentate coordination exists 
in the $\mathrm{Mg}^{2+}$-TNB complex, and the coordination distance (1.663 1.719 $\AA$ ) is shorter than that of the $\mathrm{Ca}^{2+}$-TNB system (2.029 2.154 ̊).

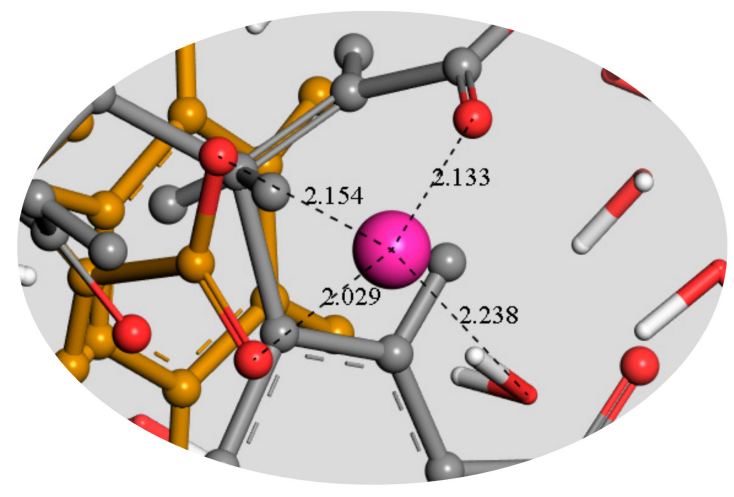

(a)

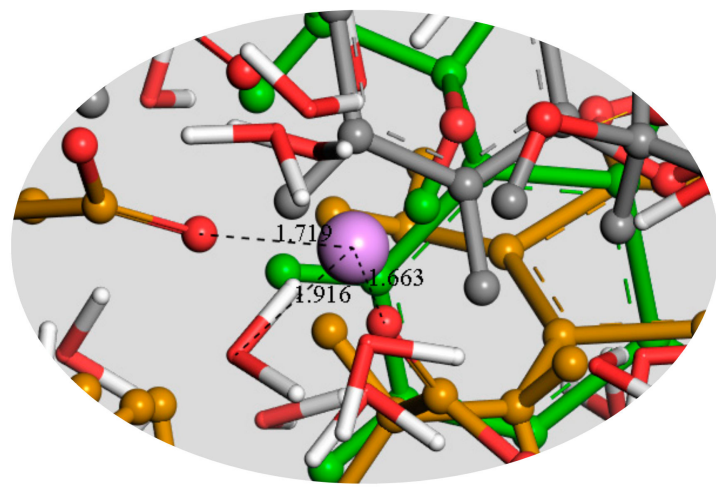

(b)

Figure 6. The coordination of TNB with (a) $\mathrm{Ca}^{2+}$ and (b) $\mathrm{Mg}^{2+}$ from snapshots of the molecular dynamics simulations. $\mathrm{Ca}^{2+}$ (pink), $\mathrm{Mg}^{2+}$ (purple), $\mathrm{O}$ (red). The coordination of water molecules with metal ions is represented by the ball stick model. The coordination between TNB and metal ions is represented by the ball bar model, the others are linear models, and the bond length is in angstroms.

\subsection{Solvent Accessible Surface Areas and Hydrogen Bonds}

As shown in Figure 7, the SASAs of TNB molecules in the studied systems under a neutral condition are calculated, and the solvent radius is set to $1.4 \AA$ [26]. Hydrophilic functional groups of TNB, such as carboxyl, hydroxyl and amino groups, play an important role in the system, and the hydrophilic region accounts for the majority of total SASAs. The interaction energy between TNB and $\mathrm{Mg}^{2+}$ decreased to $-668.28 \mathrm{kcal} / \mathrm{mol}$ at the end of the simulation. However, in the simulated $\mathrm{Ca}^{2+}-\mathrm{TNB}$ system, the interaction energy decreased slowly and finally decreased to only $-282.72 \mathrm{kcal} / \mathrm{mol}$, indicating that $\mathrm{Ca}^{2+}$ could not interact with TNB effectively (Figure 8). The SASA of $\mathrm{Ca}^{2+}-\mathrm{TNB}$ was $2300.52 \AA^{2}$, and that of $\mathrm{Mg}^{2+}$-TNB was $2145.10 \AA^{2}$. A smaller interaction between TNB and $\mathrm{Ca}^{2+}$ leads to an increase of the hydrophilic area of the $\mathrm{Ca}^{2+}$-TNB system because dispersive TNB will expose more hydrophilic groups. The above analysis shows that the interaction between TNB and $\mathrm{Ca}^{2+}$ is much weaker than that of $\mathrm{Mg}^{2+}-\mathrm{TNB}$.

The surface of TNB molecules easily forms intermolecular or intramolecular hydrogen bonds, which accelerates the aggregation of TNB molecules. The number of hydrogen bonds between functional groups of TNB was obtained using a self-made program, and the process under a neutral $\mathrm{pH}$ condition was analyzed. The aggregation process of the TNB molecule in the metal ion solution with hydrogen bonds between functional groups is shown in Figure 9. These results show that the hydrogen bonds between different functional groups of TNB molecules may be an important factor for aggregation under a neutral condition. The hydrogen bonds generated by the hydroxyl group and carboxyl group amounted to 25.3 in $\mathrm{Ca}^{2+}-\mathrm{TNB}$, and the hydrogen bonds generated by the hydroxyl and carboxyl groups amounted to 14.8 in $\mathrm{Mg}^{2+}-\mathrm{TNB}$; these values are greater than those of the other three groups. Hydroxyl and carboxyl groups are the weakest of all groups in the system. Hydroxyl and carboxyl groups are dominant in the aggregation process of HA in all simulated metal ion solutions under a neutral condition. 


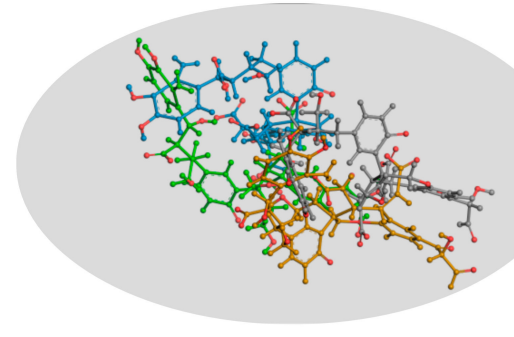

(a)

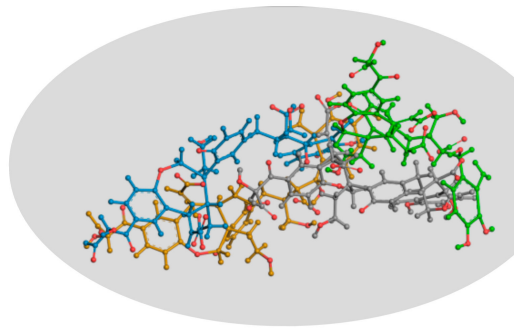

(c)

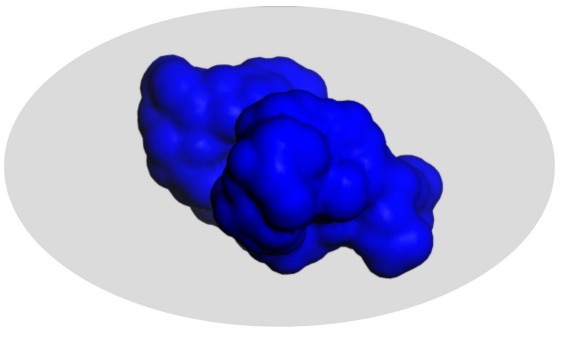

(b)

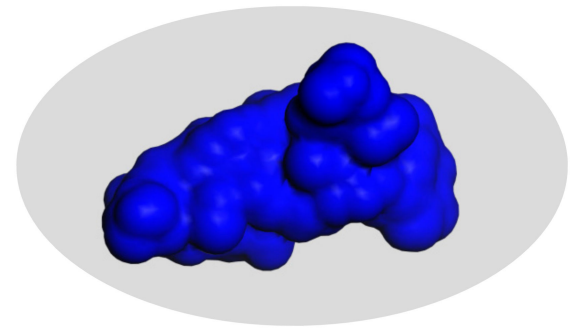

(d)

Figure 7. The morphology of TNB in (a) $\mathrm{Ca}^{2+}-\mathrm{TNB}$ and (c) $\mathrm{Mg}^{2+}-\mathrm{TNB}$ before calculation (solvent accessible surface areas) and of TNB in (b) $\mathrm{Ca}^{2+}-\mathrm{TNB}$ and (d) $\mathrm{Mg}^{2+}-\mathrm{TNB}$ after calculation.

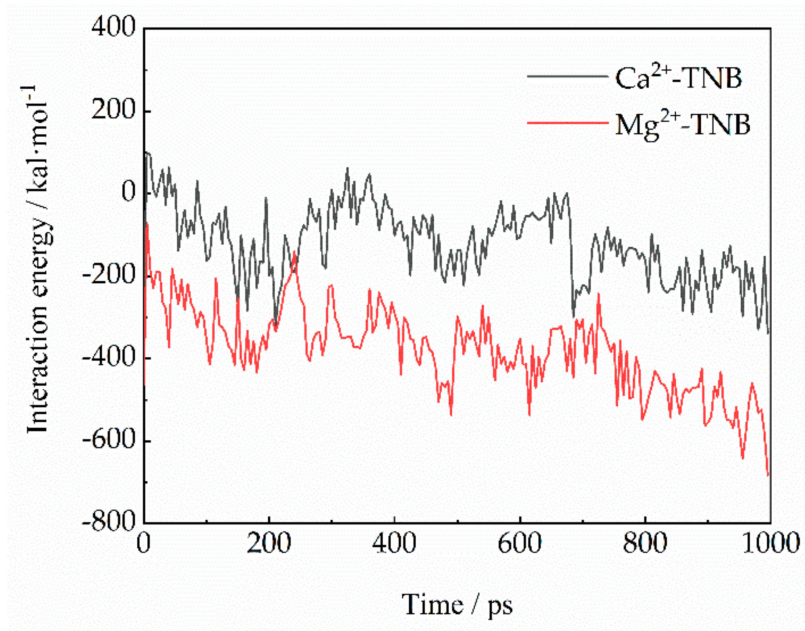

Figure 8. Interaction energy between metal ions and TNB.

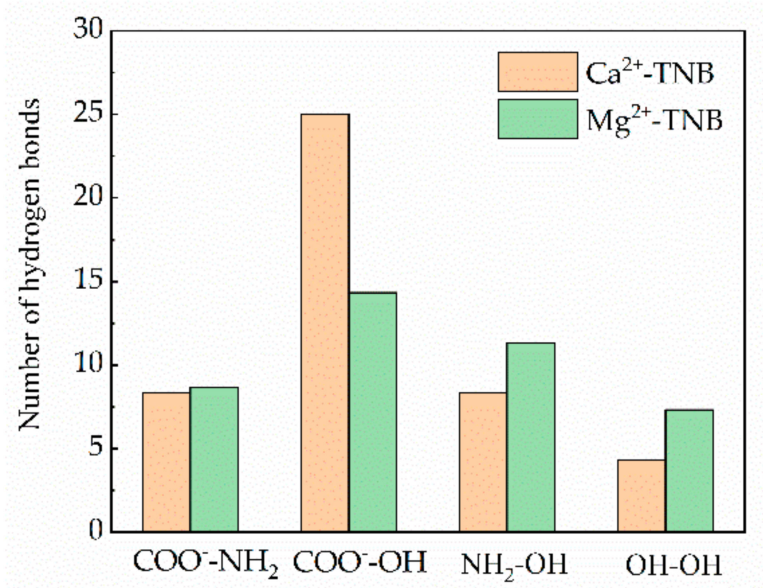

Figure 9. Number of hydrogen bonds between functional groups of TNB. 


\section{Conclusions}

The aggregation mechanism of $\mathrm{HA}$ in aqueous solutions containing $\mathrm{Ca}^{2+}$ and $\mathrm{Mg}^{2+}$ was studied by computational molecular dynamics under neutral conditions. The TNB model was used to represent HA. Under neutral conditions, the carboxyl group of TNB is deprotonated to $\mathrm{COO}^{-}$, and the negative charge of the system is neutralized by the addition of metal cations. Compared with $\mathrm{Ca}^{2+}-\mathrm{TNB}$ and $\mathrm{Mg}^{2+}-\mathrm{TNB}$, the interaction between $\mathrm{Mg}^{2+}$ and water is stronger, and so the diffusion coefficient of $\mathrm{Mg}^{2+}$ is lower. The addition of metal ions reduces the electrostatic repulsion of TNB and coordinates with the $\mathrm{COO}^{-}$and $\mathrm{OH}$ of TNB. Different coordination numbers have different effects on the aggregation behavior of TNB under neutral conditions. Metal ions can form intramolecular or intermolecular bridges with different functional groups through electrostatic synergy. $\mathrm{Ca}^{2+}$ and $\mathrm{COO}^{-}$of TNB can form bidentate (2.029 $\AA$ and $2.154 \AA$ ) complexes, while $\mathrm{Mg}^{2+}$ can only form monodentate $(2.133 \AA)$ complexes with the $\mathrm{COO}^{-}$of TNB. The interaction between TNB and $\mathrm{Ca}^{2+}$ is weaker, so the dispersed TNB in $\mathrm{Ca}^{2+}$-TNB will expose more hydrophilic groups. The SASAs of TNB in $\mathrm{Ca}^{2+}$-TNB $\left(2300.52 \AA^{2}\right)$ were found to be larger than those of TNB in $\mathrm{Mg}^{2+}$-TNB $\left(2145.10 \AA^{2}\right)$. The hydrogen bonds between hydroxyl groups and carboxyl groups are dominant in the aggregation process of $\mathrm{HA}$ in all simulated metal ion solutions under neutral conditions.

Author Contributions: X.W., Manuscript writing and revision; Y.X., review and editing; L.Y. and K.X., parameter optimization; Y.J. and N.L., parameter analysis; X.H., project administration. All authors have read and agreed to the published version of the manuscript.

Funding: National Water Pollution Control and Treatment Science and Technology Major Project of China (2017ZX07402002-05-02).

Acknowledgments: This work was supported by National Water Pollution Control and Treatment Science and Technology Major Project of China (2017ZX07402002-05-02).

Conflicts of Interest: The authors declare no conflict of interest.

\section{References}

1. Kalinichev, A.G.; Iskrenova-Tchoukova, E.; Ahn, W.Y.; Clark, M.M.; Kirkpatrick, R.J. Effects of $\mathrm{Ca}^{2+}$ on supramolecular aggregation of natural organic matter in aqueous solutions: A comparison of molecular modeling approaches. Geoderma 2011, 169, 27-32. [CrossRef]

2. Stedmon, C.A.; Thomas, D.N.; Granskog, M.; Kaartokallio, H.; Papadimitriou, S.; Kuosa, H. Characteristics of dissolved organic matter in Baltic coastal sea ice: Allochthonous or autochthonous origins? Environ. Sci. Technol. 2007, 41, 7273-7279. [CrossRef] [PubMed]

3. Leenheer, J.A. Systematic approaches to comprehensive analyses of natural organic matter. Ann. Environ. Sci. 2009, 3, 1-130.

4. Hong, S.; Elimelech, M. Chemical and physical aspects of natural organic matter (NOM) fouling of nanofiltration membranes. J. Membr. Sci. 1997, 132, 159-181. [CrossRef]

5. Ahn, W.Y.; Kalinichev, A.G.; Clark, M.M. Effects of background cations on the fouling of polyethersulfone membranes by natural organic matter: Experimental and molecular modeling study. J. Membr. Sci. 2008, 309, 128-140. [CrossRef]

6. Liu, S.S.; Zhu, Y.R.; Liu, L.Z.; He, Z.; Giesy, J.P.; Bai, Y.; Sun, F.; Wu, F. Cation-induced coagulation of aquatic plant-derived dissolved organic matter: Investigation by EEM-PARAFAC and FT-IR spectroscopy. Environ. Pollut. 2018, 234, 726-734. [CrossRef]

7. Stolpe, B.; Guo, L.D.; Shiller, A.M.; Aiken, G.R. Abundance, size distributions and trace-element binding of organic and iron-rich nanocolloids in Alaskan rivers, as revealed by field-flow fractionation and ICP-MS. Geochim. ET Cosmochim. Acta 2013, 105, 221-239. [CrossRef]

8. Yan, M.Q.; Wang, D.S.; Korshin, G.V.; Benedetti, M.F. Quantifying metal ions binding onto dissolved organic matter using log-transformed absorbance spectra. Water Res. 2013, 47, 2603-2611. [CrossRef]

9. Yamashita, Y.; Jaffé, R. Characterizing the interactions between trace metals and dissolved organic matter using excitation-emission matrix and parallel factor analysis. Environ. Sci. Technol. 2008, 42, 7374-7379. [CrossRef] 
10. Kikuchi, T.; Fujii, M.; Terao, K.; Jiwei, R.; Lee, Y.P.; Yoshimura, C. Correlations between aromaticity of dissolved organic matter and trace metal concentrations in natural and effluent waters: A case study in the Sagami River Basin, Japan. Sci. Total Environ. 2017, 576, 36-45. [CrossRef]

11. Xu, H.C.; Guan, D.X.; Zou, L.; Lin, H.; Guo, L. Contrasting effects of photochemical and microbial degradation on $\mathrm{Cu}(\mathrm{II})$ binding with fluorescent DOM from different origins. Environ. Pollut. 2018, 239, 205-214. [CrossRef] [PubMed]

12. Wu, Z.H.; Gu, Z.M.; Wang, X.R.; Evans, L.; Guo, H. Effects of organic acids on adsorption of lead onto montmorillonite, goethite and humic acid. Environ. Pollut. 2003, 121, 469-475. [CrossRef]

13. Tan, L.Q.; Yu, Z.W.; Tan, X.L.; Fang, M.; Wang, X.; Wang, J.; Xing, J.; Ai, Y.; Wang, X. Systematic studies on the binding of metal ions in aggregates of humic acid: Aggregation kinetics, spectroscopic analyses and MD simulations. Environ. Pollut. 2019, 246, 999-1007. [CrossRef] [PubMed]

14. Stirpe, A.; Rizzuti, B.; Pantusa, M.; Bartucci, R.; Sportelli, L.; Guzzi, R. Thermally induced denaturation and aggregation of BLG-A: Effect of the $\mathrm{Cu}^{2+}$ and $\mathrm{Zn}^{2+}$ metal ions. Eur. Biophys. J. Biophys. Lett. 2008, 37, 1351-1360. [CrossRef]

15. Kalinichev, A.G.; Kirkpatrick, R.J. Molecular dynamics simulation of cationic complexation with natural organic matter. Eur. J. Soil Sci. 2007, 58, 909-917. [CrossRef]

16. Ai, Y.J.; Zhao, C.F.; Sun, L.; Wang, X.; Liang, L. Coagulation mechanisms of humic acid in metal ions solution under different $\mathrm{pH}$ conditions: A molecular dynamics simulation. Sci. Total Environ. 2020, 702. [CrossRef]

17. Oren, Y.; Korngold, E.; Daltrophe, N.; Messalem, R.; Volkman, Y.; Aronov, L.; Weismann, M.; Bouriakov, N.; Glueckstern, P.; Gilron, J. Pilot studies on high recovery BWRO-EDR for near zero liquid discharge approach. Desalination 2010, 261, 321-330. [CrossRef]

18. Davies, G.; Fataftah, A.; Cherkasskiy, A.; Ghabbour, E.A.; Radwan, A.; Jansen, S.A.; Kolla, S.; Paciolla, M.D.; Sein, L.T.; Fataftah, A.; et al. Tight metal binding by humic acids and its role in biomineralization. J. Chem. Soc. Dalton Trans. 1997, 1997, 4047-4060. [CrossRef]

19. Sutton, R.; Sposito, G. Molecular structure in soil humic substances: The new view. Environ. Sci. Technol. 2005, 39, 9009-9015. [CrossRef]

20. Xu, X.; Kalinichev, A.G.; Kirkpatrick, R.J. 133Cs and 35Cl NMR spectroscopy and molecular dynamics modeling of $\mathrm{Cs}^{+}$and $\mathrm{Cl}^{-}$complexation with natural organic matter. Geochim. Cosmochim. Acta 2006, 70, 4319-4331. [CrossRef]

21. Jansena, S.A.; Malaty, M.; Nwabara, S.; Johnson, E.; Ghabbour, E.; Davies, G.; Varnum, J.M. Structural modeling in humic acids. Mater. Sci. Eng. C 1996, 4, 175-179. [CrossRef]

22. Sein, L.T.; Varnum, J.M.; Jansen, S.A. Conformational Modeling of a New Building Block of Humic Acid: Approaches to the Lowest Energy Conformer. Environ. Sci. Technol. 1999, 33, 546-552. [CrossRef]

23. Piccolo, A. The supramolecular structure of humic substances: A novel understanding of humus chemistry and implications in soil science. Adv. Agron. 2002, 75, 57-134.

24. Steelink, C. Implications of elemental characteristics of humic substances. In Humic Substances in Soil, Sediment, and Water; Aiken, G.R., McKnight, D.M., Warshaw, R.L., Eds.; Wiley: New York, NY, USA, 1985; pp. 457-476.

25. Diallo, M.S.; Simpson, A.; Gassman, P.; Faulon, J.L.; Johnson, J.H.; Goddard, W.A.; Hatcher, P.G. 3-D structural modeling of humic acids through experimental characterization, computer assisted structure elucidation and atomistic simulations. 1. Chelsea soil humic acid. Environ. Sci. Technol. 2003, 37, 1783-1793. [CrossRef] [PubMed]

26. Sutton, R.; Sposito, G.; Diallo, M.S.; Schulten, H.-R. Molecular simulation of a model of dissolved organic matter. Environ. Toxicol. Chem. 2005, 24, 1902-1911. [CrossRef] [PubMed]

27. Ritchie, J.D.; Perdue, E.M. Proton-binding study of standard and reference fulvic acids, humic acids, and natural organic matter. Geochim. Cosmochim. Acta 2003, 67, 85-96. [CrossRef]

28. Sun, H.J. COMPASS: An ab Initio Force-Field Optimized for Condensed-Phase Applications Overview with Details on Alkane and Benzene Compounds. J. Phys. Chem. B 1998, 102, 7338-7364. [CrossRef]

29. Kubicki, J.D. Molecular mechanics and quantum mechanical modeling of hexane soot structure and interactions with pyrene. Geochem. Trans. 2000, 1, 41-46. [CrossRef]

30. Tsierkezos, N.G.; Molinou, I.E. Thermodynamic Properties of Water + Ethylene Glycol at 283.15, 293.15, 303.15, and 313.15 K. J. Chem. Eng. Data 1998, 43, 989-993. [CrossRef]

31. Yuan, S.L.; Ma, L.X.; Zhang, X.Q.; Zheng, L. Molecular dynamics studies on monolayer of cetyltrimethylammonium bromide surfactant formed at the air/water interface. Colloids Surf. A Physicochem. Eng. Asp. 2006, 289, 1-9. [CrossRef] 
32. Zhao, T.T.; Xu, G.Y.; Yuan, S.; Chen, Y.; Yan, H. Molecular dynamics study of alkyl benzene sulfonate at air/water interface: Effect of inorganic salts. J. Phys. Chem. B 2010, 114, 5025-5033. [CrossRef] [PubMed]

33. Chen, Y.J.; Xu, G.Y.; Yuan, S.L.; Sun, H.-Y. Molecular dynamics simulations of AOT at isooctane/water interface. Colloids Surf. A Physicochem. Eng. Asp. 2006, 273, 174-178. [CrossRef]

34. Xu, J.F.; Zhang, Y.; Chen, H.X.; Wang, P.; Xie, Z.; Yao, Y.; Yan, Y.; Zhang, J. Effect of surfactant headgroups on the oil/water interface: An interfacial tension measurement and simulation study. J. Mol. Struct. 2013, 1052, 50-56. [CrossRef]

35. Gao, S.M.; Kang, Z.H.; Yuan, R.X.; Liu, N.; Zhu, P.; Wang, B. Molecular dynamics study of nonylphenol-substituted dodecyl sulfonate at air/water interface: Role of steric effect of surfactant headgroups. J. Mol. Struct. 2019, 1192, 35-41. [CrossRef]

36. Iskrenova-Tchoukova, E.; Kalinichev, A.G.; Kirkpatrick, R.J. Metal Cation Complexation with Natural Organic Matter in Aqueous Solutions: Molecular Dynamics Simulations and Potentials of Mean Force. Langmuir 2010, 26, 15909-15919. [CrossRef]

Publisher's Note: MDPI stays neutral with regard to jurisdictional claims in published maps and institutional affiliations.

(C) 2020 by the authors. Licensee MDPI, Basel, Switzerland. This article is an open access article distributed under the terms and conditions of the Creative Commons Attribution (CC BY) license (http://creativecommons.org/licenses/by/4.0/). 